Children's Evaluations of Third-Party Responses to Unfairness:

Children Prefer Helping Over Punishment

\author{
Young-eun Lee and Felix Warneken \\ Department of Psychology, University of Michigan \\ 530 Church St., East Hall, Ann Arbor, MI, 48109, USA
}

\begin{abstract}
Author Note
Correspondence concerning this article should be addressed to Young-eun Lee at leeyeun@umich.edu.
\end{abstract}

Acknowledgements

This research was funded by a National Science Foundation CAREER Grant (\#1253676) to FW. We thank research assistants for their help with data collection. We also thank Henry Wellman for helpful comments on the previous version of this manuscript, Amanda Golden Eddy and Amy Nowack for proofreading the manuscript and CSCAR at the University of Michigan for statistical advice. 


\begin{abstract}
Third-party punishment of selfish individuals is an important mechanism to intervene against unfairness. However, there is another way in which third parties can intervene. Rather than focusing on the unfair individual, third parties can choose to help those who were treated unfairly by reducing inequality. Such third-party helping as an alternative to third-party punishment has received little attention in studies with children. Across four studies, we examined the evaluations of third-party punishment versus third-party helping in $N=3225$ - to 9-year-old children. Study 1, 3 and 4 showed that when asked about the agents directly, children evaluated both helpers and punishers positively, but they preferred helpers over punishers overall. When asked about the type of intervention itself, children preferred helping over punishment, suggesting that their preference for the type of intervention corresponds to how children think about the agents performing these interventions. Study 2 showed that children's preference for third-party helping is driven by distributive justice concerns and not a mere preference for giving or resource maximization as children consider which type of third-party intervention decreases inequality. Together, this series of studies demonstrate that children between 5 and 9 years of age develop a sophisticated understanding of punishment and helping as two adequate forms of intervention but also display a preference for third-party helping. We discuss how these findings and prior work with adults supports the hypothesis of developmental continuity, showing that a preference for helping over punishment is deeply rooted in ontogeny.
\end{abstract}

Keywords: fairness, third-party punishment, third-party helping, development 


\section{Children's Evaluations of Third-Party Responses to Unfairness: Children Prefer Helping Over Punishment}

\section{Introduction}

Cooperation is an important feature of human social groups. While humans show extraordinary abilities to cooperate, there is often a tension between an individual's interests and those of other social partners. Fairness norms serve as a guide on how to resolve this tension, providing standards of behavior that can foster cooperation and help prevent individuals from undermining social relationships. The mere existence of fairness norms is not sufficient, as individuals might follow them imperfectly or not at all. Therefore, both theoretical models and empirical research highlight how different forms of intervention against those who violate fairness norms are important. Specifically, in direct interactions, individuals might retaliate against those who treat them unfairly or shun them to avoid further exploitation (Balliet, Mulder, \& Van Lange, 2011; Baumard, André, \& Sperber, 2013; Fehr \& Fischbacher, 2004a). Moreover, in group contexts, individuals might punish free-riders who contribute less to a public good than others, a mechanism that maintains a higher level of cooperation in the face of defection (Fehr \& Gächter, 2002; Gurerk, Irlenbusch, \& Rockenbach, 2006). These findings suggest that people enact punishment when cooperative norms are violated.

Importantly, people punish those who violate fairness norms not only when their interest is at stake but also when they are an uninvolved observer. For example, studies show that adults punish unfair resource dividers even in situations where they are a third-party who is not directly affected by the unfair allocations (Fehr \& Fischbacher, 2004a; Henrich et al., 2006; Krasnow, Delton, Cosmides, \& Tooby, 2016; Nelissen \& Zeelenberg, 2009; Yamagishi et al., 2017). More 
dramatically, adults are willing to pay a personal cost in such third-party situations by e.g. paying their own money to inflict costs on a perpetrator.

The underlying motivations for this so-called third-party punishments remain hotly disputed. One theory suggests that punishment of unfair sharing is an index of one's altruistic tendencies and concern for group norms (e.g., Fehr, Fischbacher, \& Gächter, 2002; Fehr \& Fischbacher, 2003; Fehr \& Fischbacher, 2004b). Whereas, the other theorists suggest that the underlying motivation for punishment is ultimately self-interested (Krasnow et al., 2016; Petersen, Sell, Tooby, \& Cosmides, 2010) or spiteful (Yamagishi et al., 2012, 2017). Furthermore, alternative forms of punishment such as gossip or ostracism have been discussed as well (see Guala, 2012 for ethnographic record and Molleman et al., 2019 for coordinated punishment). However, despite the disagreements over what exactly are the underlying motives, costly punishment has been identified as an important phenomenon in the study of human cooperation because it addresses the issue of how to respond to acts of free-riding (Balliet et al., 2011; Boyd, Gintis, Bowles, \& Richerson, 2003; Fehr \& Gächter, 2002; Gurerk, Irlenbusch, \& Rockenbach, 2006).

\subsection{Empirical Evidence About Third-Party Punishment in Children}

Developmental studies have only started to explore when children begin to engage in third-party punishment. Two studies using looking-time measures have found that infants expect a differential treatment of prosocial and antisocial agents. For example, 10-month-olds look longer at an event in which an unfair resource divider receives punishment than an event in which a fair resource divider receives punishment (Meristo \& Surian, 2014) and 13- to 15month-old infants differentially associate verbal praise and admonishment with fair and unfair resource dividers (Deschamps, Eason, \& Sommerville, 2015). While these studies explore 
infants' event representations and how they anticipate others would act towards fair or unfair behavior, they do not speak to infants' evaluations of these behaviors or their own third-party intervention.

Further research has shown that by around 6 years of age, children enact punishment against unfair individuals behaviorally. Three studies have shown that when in the role of a third party, 6- to 8-year-olds are willing to pay a cost to prevent inequality (Gummerum \& Chu, 2014; Jordan, McAuliffe, \& Warneken, 2014; McAuliffe, Jordan, \& Warneken, 2015). Specifically, in McAuliffe et al. (2015), children intervened selectively when dividers made unequal, selfish offers to a recipient (and did not intervene when the divider split resources equally with the recipient). This study found that this pattern emerges robustly by 6 years of age, with 5 -year-olds already trending in the same direction but not yet reliably punishing unfairness.

These studies measured children's costly punishment as a binary option (punish or not). By contrast, Smith and Warneken (2016) asked children to judge the amount of rewards or punishment hypothetical actors should receive for doing more or less of a good deed (e.g. cleaning windows) or bad deed (e.g. muddy footprints on the carpet). They found that 6- to 10year-old children, but not 4- to 5-year-olds, assigned more aversive jobs to those who showed more blameworthy behaviors. Thus, as they grow older, children allocate punishment in proportion to the amount of blameworthy behaviors, suggesting the development of desert-based punishment.

While studies described above demonstrate when children begin to punish unfair individuals in resource allocation contexts, other studies have focused on other types of norm violations. For example, when 3-year-olds observed how one puppet destroyed another puppet's belongings (e.g., ripping apart a picture), they protested verbally (e.g., "No, you're not supposed 
to do that.”) or tattled on the transgressor (Vaish, Missana, \& Tomasello, 2011). In a similar moral transgression, 3- to 6-year-olds punish the transgressor by taking away his or her opportunity to engage in a fun, desirable activity (Yudkin, Van Bavel, \& Rhodes, 2020). Furthermore, by 2 years of age, children can identify an individual who deserves punishment and act based on it, such as selectively taking away a treat from an antisocial agent who had hindered another person's goal over a prosocial agent who had been helpful (Hamlin, Wynn, Bloom and Mahajan, 2011).

In sum, existing research shows that in situations involving helping or hindering one's instrumental goal, 2-year-olds already direct rewards or punishment towards agents based on desert (Hamlin et al., 2011). By 3 years of age, children intervene against moral transgressions by reproaching verbally (Vaish et al., 2011) or by preventing access to activities after a property damage (Yudkin et al., 2020). Around 6 years, children systematically intervene against fairness norm violations, punishing unfair allocations more often than fair allocations (McAuliffe et al., 2015) and endorsing relatively more punishment to more severe norm violations (Smith \& Warneken, 2016). Therefore, as children grow older, they not only intervene against an increasing range of transgressions — from goal hindrance, ownership violations to fairness violations — but also intervene in a systematic and selective manner.

\subsection{Helping as an Alternative Intervention}

Notwithstanding the important insights gained from studies of third-party punishment, it is by no means the only way to intervene against moral transgressions. For example, rather than punishing the agent of the act, a third party might choose to help the patient who has been placed at a disadvantage. With punishment targeting the perpetrator and helping targeting the recipient of unfair treatment, third-party punishment and helping focus on different aspects of justice 
restoration. While third-party punishment has been studied extensively with adults and to some extent in children, very little research has been devoted to third-party helping, despite its equal importance.

Several experiments have tested whether adults want to help or punish when they are the third party. Some studies find that adults would rather like to help the recipient than to punish the perpetrator (Chavez \& Bicchieri, 2013; Jordan, Hoffman, Bloom, \& Rand, 2016), although others found the reverse preference (e.g., FeldmanHall et al., 2014; Stallen et al., 2018). Findings are more consistent with how adults evaluate punishers and helpers. Overall, adults prefer third parties who help recipients over those who punish transgressors. For example, when observing how one person was unfair to a recipient, adults were more likely to reward a third-party helper who gave resources to the recipient rather than a third party who punished the unfair divider (Raihani \& Bshary, 2015a). Similarly, further studies showed that helpers were perceived to have superior moral character (e.g., warmth) compared to punishers (Patil, Dhaliwal, \& Cushman, 2018) and are more likely to be trusted as a partner in economic interactions (Jordan et al., 2016; Patil, Dhaliwal, \& Cushman, 2018). These results imply that third-party helping is not only regarded as a viable, important response to unfairness but also gains an even more positive reputation than punishment.

\subsection{Evaluations of Punishers in Children}

Despite the importance of helping as a critical form of third-party responses, no research has investigated how children think about helpers in comparison with punishers. Previous work focused on comparing third-party punishers with those who failed to adequately intervene. For example, in an interaction involving physical aggression (e.g., a perpetrator chasing and hitting the victim), 6-month-old infants were more likely to touch a third-party agent who intervened by 
blocking the perpetrator from the victim over another third-party who did not intervene, demonstrating a preference for intervenors (Kanakogi et al., 2017). Another study (Hamlin et al., 2011) tested infants' preferences in a context that involves helping or hindering one's goal. When infants had to choose between a taker-puppet who had removed a treat from a goalhinderer and a giver who had handed a treat to the goal-hinderer, 8-month-olds, but not 5-montholds, preferred the taker over the giver, suggesting that they like those who punish hinderers better than those who help hinderers.

In Vaish, Herrmann, Markmann and Tomasello (2016), 4- and 5-year-olds watched scenarios in which a transgressor broke a moral norm (e.g., one person destroying another person's belongings). Subsequently, one third-party enforced the norm verbally (e.g., "Don't ever do that again"), whereas the other third-party made neutral comments. Results showed that 5-year-olds, but not 4-year-olds, evaluated norm-enforcers more positively than non-enforcers. Hence, in a context of ownership violations, children's own spontaneous verbal protest emerges around 3 years (Vaish et al., 2011), whereas it is not until 5 years of age that children reflect on the behaviors of a third party and like those who verbally enforce norms more than those who do not. Taken together, the studies with infants and children suggest their preference for punishers over non-punishers in various forms of moral transgression.

These studies provide insight into children's evaluation of third-party punishers. However, what is not known is whether children choose punishers because they like them or merely because they are paired with more negatively valenced individuals. Specifically, punishers have been compared with bystanders who witnessed the transgression but chose not to intervene (e.g., Kanakogi et al., 2017, Vaish et al., 2016) or with givers who helped the 
transgressor (e.g., Hamlin et al., 2011). It is therefore not clear whether they evaluate punishers positively or just not as negative as the alternative agent.

Moreover, prior research focused exclusively on moral transgressions such as hindering one's goal (e.g., Hamlin et al., 2011), physical aggression (e.g., Kanakogi et al., 2017) and property damage (e.g., Vaish et al., 2011; Vaish et al., 2016). Equally important to consider is how children evaluate the punishment of transgressors when fairness norms are violated. As illustrated earlier, third-party punishment is an important mechanism for dealing with individuals who violate fairness norms.

\section{Current Study}

Here we aim to examine (1) whether children evaluate third-party punishers positively or negatively and (2) how punishers are evaluated in comparison with helpers focusing specifically on fairness violations. To our knowledge, it has not been studied how children evaluate punishers versus helpers when they are presented as two options to respond to unfairness. Given the finding that adults prefer helpers over punishers, it is important to investigate how children think about these forms of intervention and to trace its developmental trajectory.

One hypothesis is that children would show a pattern of results similar to adults. That is, regardless of their age, children might evaluate both helpers and punishers positively overall, but when forced to choose, they might regard helpers as even more positive than punishers. Under this hypothesis, the preference of adults for helpers over punishers is a psychological phenomenon that already appears early in development when children begin to reason about third-party punishment.

A plausible alternative hypothesis is that children undergo major developmental changes in their preferences, where young children evaluate only helpers positively, while they view 
punishers as negative or neutral at best potentially due to punishment being an antagonistic behavior (i.e., taking resources away from a person). With increasing age, children might evaluate punishers more positively as they gain a better understanding of potential benefits of punishment such as maintenance of norms and deterrence of transgressions (see Bregant, Shaw, \& Kinzler, 2016 for children's understanding of the deterrent effect of punishment).

Here we present a series of studies comprising a pilot study to validate our new task and four studies to address the above hypotheses.

\subsection{General Methods}

2.1.1. Experimental design and procedure. Across four studies, children heard a story about four actors — one divider, one recipient and two third parties — who played a candy game at a summer camp. The experimenter walked children through the story with visual aids by using paper-cut actors and candies. The actors were matched to the gender of the participant.

At the beginning of the story, the divider and the recipient have two candies each. Then, the divider can decide how to divide the additional two candies (see Figure 1). Children were told that the divider can keep both candies or give some of the candies to the recipient. 


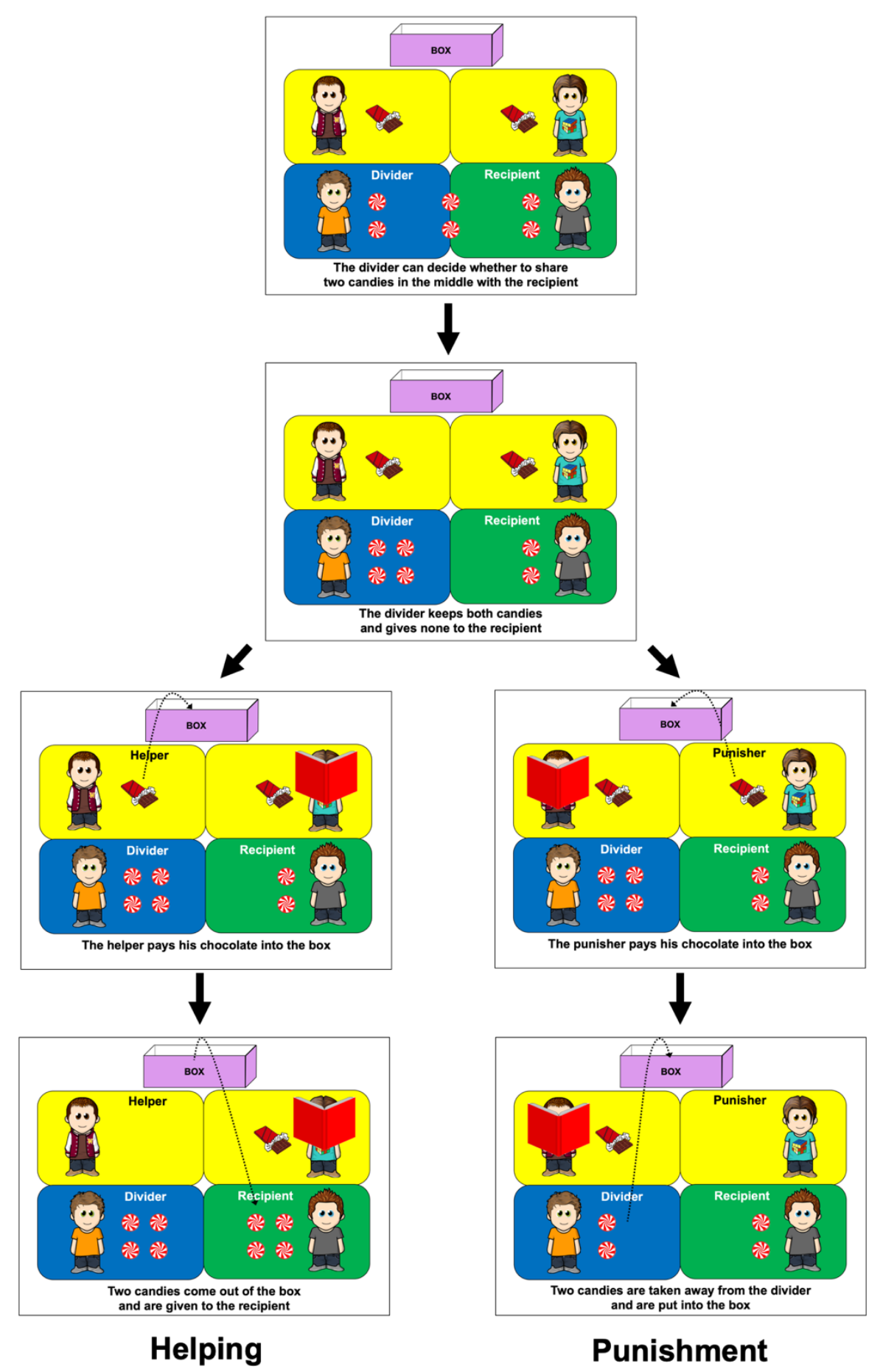

Figure 1. Schematic set-up of stimuli used in Study 1.

The two panels at the top show an unfair allocation. The two panels on the left show a helping scenario, while those on the right show a punishment scenario. Each panel shows the laminated figures and objects used by the experimenter to illustrate the different scenarios to the child. The labels "Helper", "Punisher" etc. are added here for reading comprehension. Children never heard the word "helper" or "punisher" at any point in the story. 
In fact, because we were interested in how children respond to fairness violations, the divider always kept both candies for themselves, resulting in unequal allocation ( $4: 2$ between the divider and recipient).

Before showing children an unfair allocation made by the divider, we assessed whether children endorse sharing by asking what number of candies the divider should give to the recipient. It was important to confirm that children endorse sharing because otherwise, they would not be able to understand the purpose and intention of third-party intervention. Across four studies, a majority of children (80\%) endorsed equal sharing (i.e., sharing 1 out of 2 candies) (65 out of 80 participants in Study 1, 62 out of 80 participants in Study 2, 65 out of 80 participants in Study 3, and 66 out of 82 participants in Study 4), and the remaining 20\% stated the divider should give 2 out of 2 candies to the recipient, $\chi^{2}(1)=116.9, p<.001$. We excluded children from analyses if they considered it acceptable for the divider not to share with the recipient (i.e., giving 0 candies).

After seeing the unfair allocation, each child heard both punishment and helping scenarios. In each scenario, the third parties have three options: (1) give two candies to the recipient by paying own chocolate (i.e., costly helping), (2) take two candies away from the unfair divider by paying own chocolate (i.e., costly punishment) or (3) do nothing. In the helping scenario, one of the two third parties decides to give two candies to the recipient by paying his or her own chocolate (see Figure 1 and Table 1). By contrast, in the punishment scenario, the other third-party decides to take two candies away from the unfair divider by paying a chocolate. The payment of a chocolate in this case represents a personal cost that the third-party has to bear. We made each third-party intervention costly because the payment of a cost could remove the doubt in observers that the third-party's intervention is motivated by a self-serving desire and can 
signal that the third-party genuinely cares about others (Balliet et al., 2011; Nelissen, 2008; Raihani \& Bshary, 2015b). In each scenario, only one of the two third-parties was involved. Children were told that the other third-party who was not involved in a given scenario was reading a book. This was to prevent children from blaming the non-involved third-party for not intervening.

Table 1

Experimental design with resource allocation (Divider:Recipient)

\begin{tabular}{|c|c|c|c|c|c|}
\hline Study & Condition & Scenario & $\begin{array}{c}\text { Before } \\
\text { Intervention }\end{array}$ & $\begin{array}{c}\text { After } \\
\text { Intervention }\end{array}$ & $\begin{array}{c}\text { Inequality } \\
\text { Between } \\
\text { Divider and } \\
\text { Recipient }\end{array}$ \\
\hline \multirow{2}{*}{$\begin{array}{c}\text { Study } \\
1,3 \& 4\end{array}$} & & Helping & \multirow{2}{*}{$4: 2$} & $4: 4$ & 0 \\
\hline & & Punishment & & $2: 2$ & 0 \\
\hline \multirow{4}{*}{ Study 2} & Helping & Rational & \multirow{2}{*}{$4: 2$} & $4: 4$ & 0 \\
\hline & Only & Irrational & & $6: 2$ & 4 \\
\hline & \multirow{2}{*}{$\begin{array}{c}\text { Punishment } \\
\text { Only }\end{array}$} & Rational & \multirow{2}{*}{$4: 2$} & $2: 2$ & 0 \\
\hline & & Irrational & & $4: 0$ & 4 \\
\hline
\end{tabular}

After hearing both scenarios, children were asked test questions. Two primary measures were kept constant across four studies: (1) Children's liking of each third-party actor on a 7-point smiley face Likert scale and (2) their forced-choice preference between the two third parties (e.g., who do you like better?).

During the warm-up phase (i.e., before children heard the story), children practiced how to use a Likert scale to indicate their liking (Study 1 through 4) and their agreement about an 
action (Study 3 and 4). Children were asked to point to one of the faces on the Likert scale for something they really like or really do not like, ranging from -3 (do not like it at all) to +3 (like it a lot). Also, they were asked to point to a face on the Likert scale for something they strongly agree or strongly disagree, ranging from -3 (totally disagree) to +3 (totally agree). Children's responses during the practice confirmed that they can use the Likert scale to indicate their agreement in a flexible manner (see the supplementary material for more detailed results from the practice).

We define third-party helping as a third-party's compensation of payoffs to another individual. This term was used for consistency with other similar studies with adults (e.g., Raihani \& Bshary, 2015a; Jordan et al., 2015).

In all four studies, we counterbalanced the order of scenarios (punishment scenario first vs. helping scenario first), the order of the Likert scale (introduce positive rating first vs. negative rating first), the order of comprehension check questions, the order of test questions and appearances of third-party actors.

2.1.2. Data coding and analyses. Children's responses were live coded by the experimenter and later checked by an independent video coder. Disagreements between live and video coding were resolved by re-watching the video. All statistical analyses were conducted with R statistical software ( $\mathrm{R}$ version 3.5.2; R Core Team, 2018). In our analyses, we entered the age in months, not in years.

In all studies, we analyzed children's endorsement of equal sharing with a goodness-of-fit chi-square test, their responses in the Likert scale rating with one sample t-tests (two-tailed) and their responses in the forced-choice measures with binomial tests (two-tailed). To test the effect of age, we ran Linear Mixed Models (LMM) on the Likert scale ratings using the package 'nlme' 
(Pinheiro et al., 2018), Generalized Linear Models (GLM) on the social preference scores and Generalized Linear Mixed Models (GLMM) on forced choices using the package 'lme4' (Bates, Maechler, Bolker, \& Walker, 2015).

Our analysis procedure was as follows: (1) we examined a null model, which included only subject ID in mixed models and only intercept in the linear models; (2) we created a full model, which included our main predictors (e.g., intervention type, age in months) and all interactions among the predictors; (3) we compared the full model with the null model; (4) if the full model provided a significantly better fit to the data, we created a minimal model by sequentially dropping single terms from the full model, testing whether their inclusion improved the model fit; (5) we stopped this process and finalized our minimal model when dropping single terms no longer provided a better fit to the data.

We proceeded to test individual predictor variables only if the full model with predictors provided a significantly better fit to the data than the null model. Moreover, since the current four studies comprised a large number of analyses, for the sake of brevity and clarity, we report test statistics only for the final model, while all model comparisons are included in the supplementary material. Figures show predicted estimates with 95\% confidence intervals based on the final model. All data and protocols are available through the Open Science Framework: https://osf.io/8wxtj/?view_only=f46dc44bf88845cbb93016a91371d62d.

\section{Pilot Study}

In our pilot study, we tested $N=326$ - to 7 -year-old children. We chose this initial age because prior work had established that children 6 years and older reliably detect violations of fairness norms and are willing to punish transgressions (e.g., Jordan et al., 2014; McAuliffe et al., 2015). We piloted our aforementioned task, where children heard about a third-party who 
punished an unfair divider, whereas another third-party helped the recipient of the unfair allocation. Our dependent measures were children's liking of each third-party character measured on a 7-point Likert scale and a forced-choice task to choose between the punisher or the helpers. This pilot established that children were able to follow the story, the task, and the measures, as established through comprehension checks. Moreover, the results indicated that children evaluated both third parties positively, but they tended to prefer helpers over punishers (see the supplementary material for more details). After this first validation, we made minor modifications to streamline the procedure and used this method for a series of four studies. For these studies, we broadened the age range to 5- to 9-year-olds to examine potential developmental change.

\section{Study 1: How Do Children Evaluate Helpers and Punishers?}

\subsection{Method}

4.1.1. Participants. Our final sample were $N=805$ - to 9 -year-old children $(M=89.33$ months, range $=60-118$ months, $n=16$ participants in each age group, 40 female). Children were recruited and tested in a public park in an urban area in the US. After parental consent, children were brought to a table with the study apparatus while the parents watched from a few steps away, instructed not to intervene. Demographic information such as race, education, and income were not assessed in this context. Fourteen additional children were excluded because they failed to identify the helper and punisher during both memory check questions (9) or they did not endorse sharing and said that the divider should give zero candies to the recipient (5).

4.1.2. Experimental design and procedure. We used the same basic design and procedure described in General Methods (see 2.1.1), with the following additional measures. In the forced-choice questions, we asked not only who they like better between the helper and the 
punisher (labeled "like better") but also who they want to be friends with (labeled "friend"), who they want to invite to their party (labeled "party").

Furthermore, to explore children's reasoning behind their preference for punishers and helpers, we tested whether children attribute relevant traits to either the punisher or helper. For instance, children were asked who is more likely to get into a fight (to see if they attribute “aggression" to punishers), who is more likely to tell a person who cut in line to go back (to see if they attribute "norm enforcement" to punishers), who is more likely to give more turns to ride a bike to others (to see if they attribute "generosity" to helpers), and who is more likely to comfort a crying child (to see if they attribute "empathy" to helpers). These forced-choice trait attribution questions were asked with other social preference questions (e.g., like better, friend, party) during the test phase. Our trait attribution tasks measured a relative trait inference (e.g., "helper is more generous than punisher") instead of whether children reasoned about a single person (e.g., "helper is generous") (see Liu \& Vanderbilt, 2013).

\subsection{Results}

\subsubsection{Evaluations in Likert scale ratings. Children evaluated both the helper and the} punisher positively. Children's evaluation of both the helper $(M=2.15, S D=1.29)$ and punisher $(M=1.84, S D=1.35)$ differed significantly from neutral (one sample t-tests; $t(79)=14.87, p<$ .001 and $t(79)=12.14, p<.001$, respectively). The results from an LMM indicated that neither age nor intervention type (helper vs. punisher) had a significant effect on children's ratings (see the supplementary material for analyses). These analyses show that children's ratings of helpers and that of punishers did not differ significantly at all ages (see Figure 2A). The result from a paired t-test revealed that children tended to rate the helper more positively than the punisher with a marginal significance, $t(79)=1.72, p=.09$. 
4.2.2. Social preference in forced-choice questions. We first analyzed all three preference questions separately. Children chose helpers over punishers when asked who they liked better $(73 \%$; binomial test, $p<.001)$ and who they wanted to invite to their party $(66 \%, p<$ .01). However, their preference for helpers did not differ from chance when asked who they would choose as a friend $(60 \% ; p=.09$; see Table 2 and Table S1 in the supplementary material for values broken down by age group). One question is why children's preference was more pronounced in the 'like better' question than in 'party' or 'friend' questions (note that the preferences in these two questions were trending towards helpers as well). We speculate that the friend and party questions might involve other social motivations. For example, regardless of who they like personally, some children might want to associate with the punisher who might seem socially dominant or seem to have power and assertiveness. By contrast, the 'like better' question is a more direct and pure measure of social preference per se.

Children's responses in the three forced-choice questions (friend, party and like better) were intercorrelated (Cronbach's $\alpha=.63$ ). Thus, in subsequent analyses, we averaged responses to the three forced-choice questions for each child, which we refer to as the social preference score $($ helper $=1$, punisher $=0)$ with higher values reflecting a preference for helpers over punishers. The results from a full GLM including age as a fixed effect revealed that there was no significant effect of age on children's social preference score, $\chi^{2}(1)=2.02, p>.15$ (see Figure 2C). Overall, in the forced-choice preference questions, children preferred helpers to punishers irrespective of their age. 
A

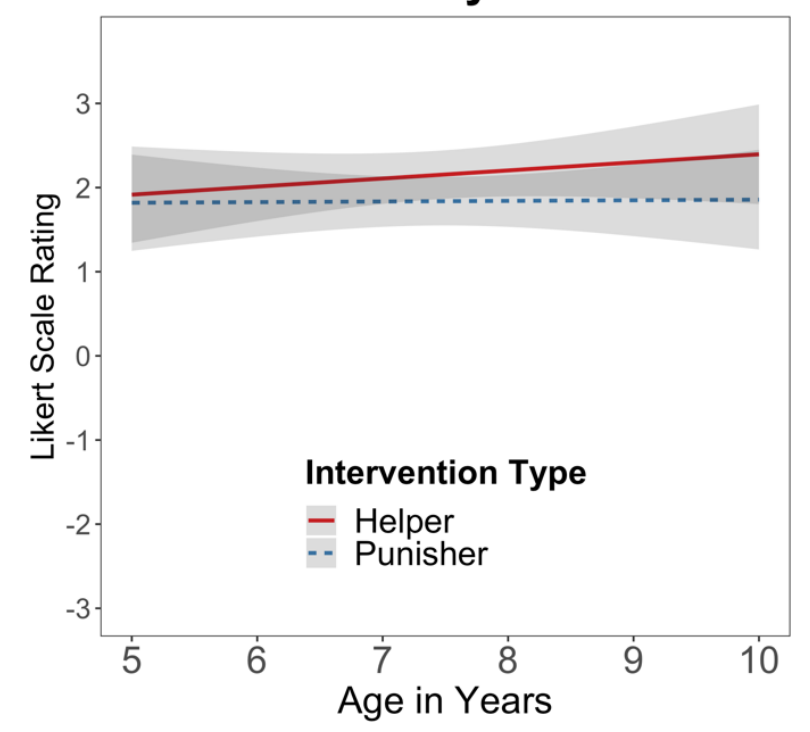

C

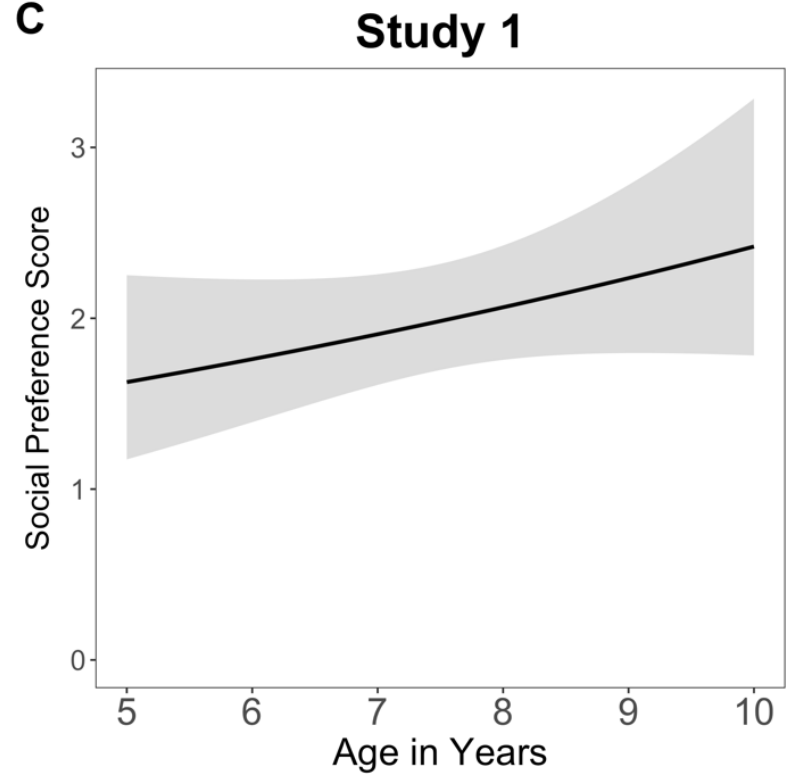

B

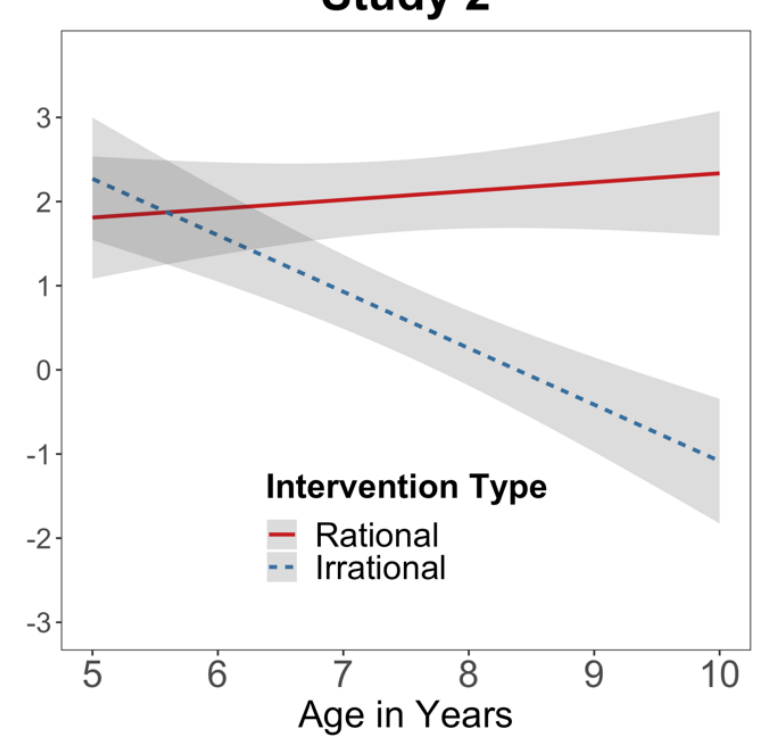

D

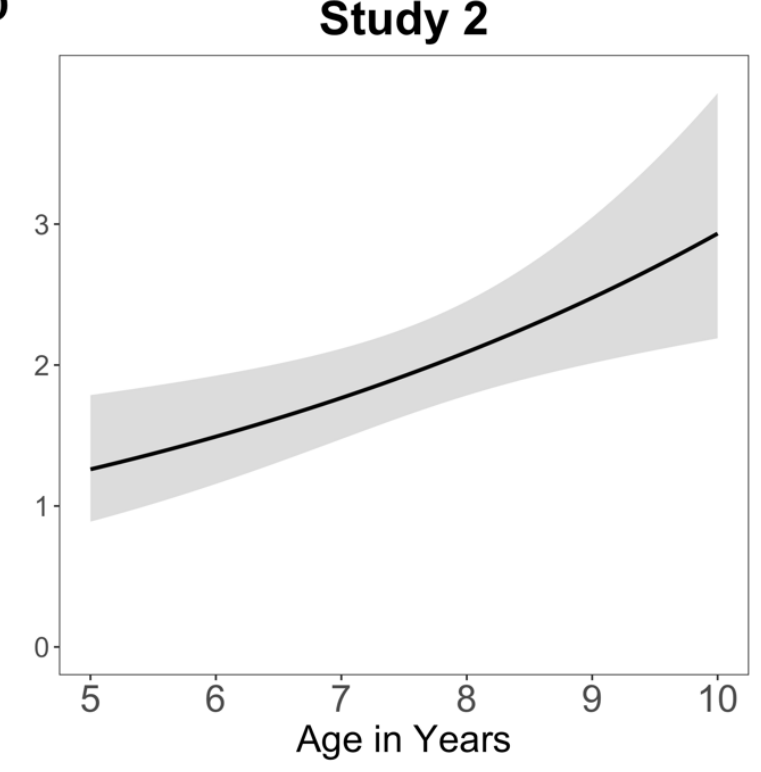

Figure 2. Likert scale ratings and social preference scores in Study 1 and 2.

(A) Likert scale ratings of helpers and punishers in Study 1. (B) Likert scale ratings of rational and irrational third parties in Study 2. (C) Higher score indicates children's preference for helpers over punishers in Study 1. (D) Higher score indicates children's preference for rational over irrational third parties in Study 2.

Table 2

Mean proportion of children who chose helpers over punishers (Study 1) and those who chose rational over irrational third parties (Study 2) in binomial tests collapsed across age. 


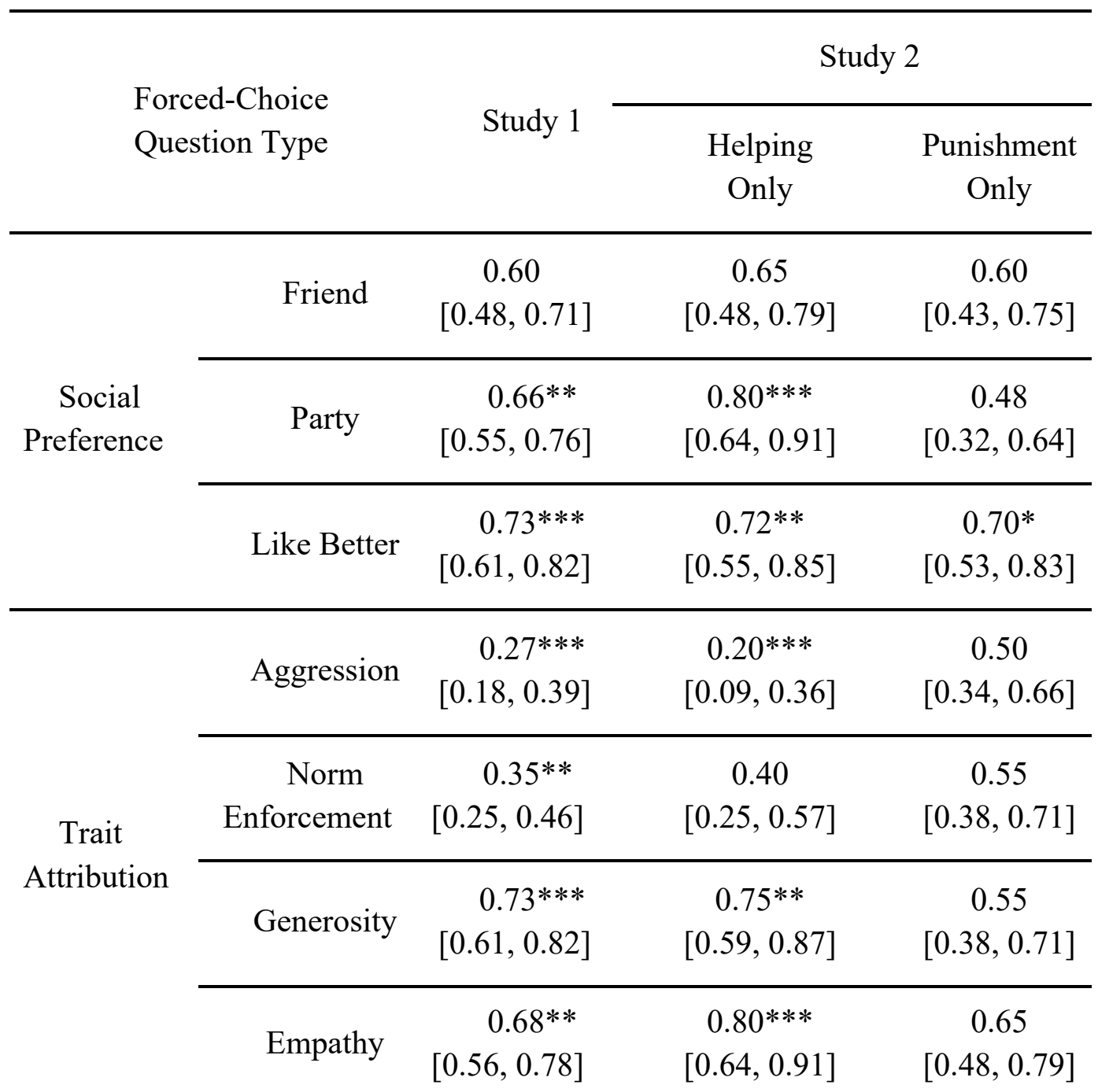

Note. The numbers in parentheses represent $95 \%$ confidence intervals.

$* p<.05, * * p<.01, * * * p<.001$

4.2.3. Trait attribution. Children attributed relevant traits to the third parties: Children attributed generosity (73\%; binomial test, $p<.001)$ and empathy $(68 \% ; p=.002)$ to helpers, while they attributed aggression $(73 \% ; p<.001)$ and norm enforcement $(65 \% ; p<.01)$ to punishers (see Table 2). These results suggest that children attributed warmth-related traits (generosity, empathy) to helpers and conflict-related traits (aggression, norm enforcement) to 
punishers, providing converging evidence with their preference for helpers over punishers (see the supplementary material for more detailed results about trait attribution).

\subsection{Discussion of Study 1}

Study 1 showed that children evaluate both third parties positively and their ratings did not differ from each other significantly on the Likert scale. In forced-choice tasks, however, children preferred helpers over punishers. There were no age-related changes in either the Likert scale ratings or forced-choice social preference questions. Children inferred that helpers were more likely to show warmth-related traits (generosity, empathy), while punishers were more likely to show conflict-related traits (aggression, norm enforcement).

However, there are at least two alternative explanations for children's preference for helpers over punishers. One possible explanation is that children prefer helpers not because they reason about responses to unfair treatment but merely because they prefer givers over takers. They might have associated giving with positive evaluation and associated taking with negative evaluation. To address this alternative hypothesis, it is important to test if children like givers regardless of whether justice is restored or not. Another alternative account that could explain our previous results is that children might have preferred those who maximize resources. Concretely, in our setup, helping always resulted in more resources for the actors than punishment. For instance, helping resulted in 4:4 (8 candies in total), while punishment leads to 2:2 (4 candies in total). Under this hypothesis, children do not care about rectifying inequality, but simply think that increasing rewards is generally better. Study 2 was designed to address these possibilities.

\section{Study 2: Do Children Merely Prefer Givers or Resource Maximizers Without}




\subsection{Method}

5.1.1. Participants. Our final sample were $N=80$ 5- to 9 -year-old children. One half of the children were assigned to the helping-only condition and the other half to the punishmentonly condition. In the helping-only condition, our sample were $n=40(M=89.80$ months, range $=60-116$ months, 8 participants in each age group, 20 female). In the punishment-only condition, our sample were $n=40(M=88.90$ months, range $=60-119$ months, 8 participants in each age group, 20 female). Children were drawn from the same population and tested in the same context as children from Study 1. Twelve additional children were excluded either because they failed to identify the rational and irrational third parties during both memory check questions ( 4 in the helping only condition, 5 in the punishment only condition) because they did not endorse sharing ( 1 in the helping only condition), or there was an experimental error ( 1 in the helping only condition, 1 in the punishment only condition).

5.1.2. Experimental design and procedure. The measures used in Study 2 were identical to those in Study 1. To address the two possible alternative explanations described above, we tested children in two between-subject conditions. In the Helping-only condition, children's preference for the rational helper was compared with that for the irrational helper. The irrational helper gives two candies to the unfair divider, while the rational helper gives two candies to the recipient. In the Punishment-only condition, the irrational punisher who takes two candies away from the recipient was compared with the rational punisher who takes two candies away from the unfair divider (see Table 1).

If children's preference for helpers in Study 1 was due to their preference for givers to takers, we would expect no difference between irrational and rational helpers in the helping only condition. By contrast, if children in Study 1 made a judgment in terms of fairness, children in 
the current study would prefer rational over irrational helpers. Additionally, if children based their preference on those who maximize a total number of resources, there should be no difference in their preference between rational and irrational third parties as both rational and irrational third-party intervention result in the same amount of candies in each condition. By contrast, if those in Study 1 made a judgment in terms of fairness, they would prefer rational to irrational third parties in both conditions.

\subsection{Results}

5.2.1. Evaluations in Likert scale ratings. In the helping only condition, children's evaluation of rational helpers $(M=2.08, S D=1.59)$ differed significantly from neutral, one sample t-tests, $t(39)=8.25, p<.001$, implying that they evaluated rational helpers positively. In contrast, the evaluation of irrational helpers $(M=0.60, S D=2.05)$ did not differ from neutral; $t(39)=1.85, p>.07$. In the punishment only condition, in which children were presented with rational and irrational punishers, their evaluation of the rational punisher $(M=2.10, S D=1.28)$ differed significantly from neutral; $t(39)=10.4, p<.001$. The ratings for the irrational punisher $(M=0.70, S D=1.98)$ differed from neutral; $t(39)=2.24, p=.03$.

We ran a full LMM on the Likert scale ratings with condition (helping only vs. punishment only), intervention type (rational vs. irrational), and age and interactions with the predictors as fixed effects and subject ID as a random effect. The results revealed that there were no interaction effects involving condition (all $p s>.60$; see the supplementary material for detailed analyses). This shows that children's evaluations of third-party actors were similar for the helping only and punishment only conditions. Critically, there was a significant interaction between intervention type and age, $\operatorname{LRT}, \chi^{2}(1)=19.08, b=-0.06, S E=0.01, p<.001$, indicating that children's evaluations of rational vs. irrational actors changed with age (see Figure 2B). 
To unpack the interaction effect between intervention type and age, we ran separate LMMs for rational and irrational characters. We found that children's evaluation of rational third parties did not change depending on their age, $\chi^{2}(1)<1, p>.62$. Whereas, children's age significantly predicted their rating of irrational characters, $\chi^{2}(1)=21.96, b=-0.06, S E=0.01, p$ $<.001$, suggesting that children evaluated irrational third parties negatively as they grow older.

To assess the age at which children's rating of irrational third parties differs from that of rational ones, we computed the age point when confidence intervals no longer overlapped with each other. We found that around 82 months of age, children's rating of irrational actors becomes lower than rational ones in both the helping only (rational $M=2.00,95 \% \mathrm{CI}[1.55$, 2.45]; irrational $M=1.04,95 \%$ CI $[0.59,1.49]$ ) and punishment only conditions (rational $M=$ $2.04,95 \%$ CI $[1.60,2.49]$; irrational $M=1.08,95 \%$ CI $[0.63,1.53])$. These results suggest that children's understanding of the justifiability of third-party interventions becomes robust by 7 years of age. Therefore, the preference for helpers over punishers by children 7 years and older found in Study 1 cannot be explained by a mere preference for givers or for resource maximizers.

5.2.2. Social preference in forced-choice questions. In the helping-only condition, children's preference for rational helpers over irrational helpers increased with age from $50 \%$ in 5-year-olds to $88 \%$ in 9-year-olds when asked who they liked better. In friend and party questions, they showed a similar age-dependent increase in the preference (from $38 \%$ to $75 \%$ in the friend question and from $63 \%$ to $75 \%$ in the party question). In the punishment-only condition, similar patterns were observed. Children's preference for rational punishers over irrational punishers increased with age from 50\% in 5-year-olds to $88 \%$ in 9 -year-olds when asked who they liked better. The preference for rational punishers increased with age from $25 \%$ 
to $88 \%$ in the friend question and from $25 \%$ to $63 \%$ in the party question (see Table S2 in the supplementary material for values broken down by age group).

Children's responses to the three forced-choice questions (rational third-party $=1$, irrational third-party $=0$ ) were averaged into a social preference score because their responses in the three forced-choice questions (friend, party and like better) were highly intercorrelated (Cronbach's $\alpha=.78$ ). A higher score indicates a stronger preference for rational over irrational third parties. The results from a full GLM including condition (helping only vs. punishment only), age and the interaction between condition and age as fixed effects revealed that there was neither main effect nor interaction effect involving condition (all $p \mathrm{~s}>.25$; see the supplementary material for analyses). However, we found a significant effect of age on children's social preference score, $\chi^{2}(1)=9.06, b=0.01, S E=0.004, p<.01$ (see Figure 2D). This suggests that with increasing age, children were more likely to prefer rational over irrational actors.

To assess the age at which children's preference for rational over irrational third parties becomes reliable, we computed the age point when confidence intervals no longer overlapped with the value of 1.5 , which is the social preference score expected by chance. Results revealed that from 85 months of age, confidence intervals no longer overlapped with $1.5(M=1.79,95 \%$ CI $[1.502,2.14])$. This suggests that a preference for rational over irrational third parties becomes more reliable around age 7 . Taken together, the findings from social preference scores as well as those from Likert scale ratings support that children gain a better understanding of proper targets of third-party interventions around 7 years of age.

5.2.3. Trait attribution. In the helping-only condition, children attributed empathy (80\%; binomial test, $p<.001)$ and generosity $(75 \% ; p<.01)$ to rational helpers than to irrational helpers. This suggests that even though both helpers showed the same giving behaviors, children 
infer warmth-related traits from rational helpers who restored recipients' loss rather than from irrational ones who rewarded selfish dividers. Also, children in the helping only condition attributed aggression to irrational helpers $(80 \% ; p<.001)$. However, their attribution of norm enforcement was not significant ( $p>.26$; see Table 2). It is perhaps not surprising that children had difficulties with attributing norm enforcement to one of the helpers because the focus of helping is to restore recipients' loss, not to enforce norms on perpetrators.

In the punishment-only condition, we predicted that children would attribute generosity, empathy and norm enforcement to rational punishers while attributing aggression to irrational punishers. However, this was not the case: there were no consistent attributions of traits to either kind of punisher (all $p \mathrm{~s}>.08$; see Table 2 and supplementary material for detailed results about trait attribution). One possibility is that the taking behavior that both punishers displayed might have made children perceive both punishers as an aggressive individual regardless of their rationality, preventing them from appreciating underlying personality traits of justifiable vs. unjustifiable punishment. These results in the punishment-only condition contrast with children's successful trait attribution in the helping-only condition in which both helpers did not show taking behavior or Study 1 in which only one of two third parties showed taking behavior.

\subsection{Discussion of Study 2}

Study 2 revealed that, from age 7, children like rational actors who decrease inequality more than irrational actors who increase inequality in both continuous Likert scale ratings and forced-choice measures. This shows that by 7 years of age, children have a sophisticated understanding of justifiable third-party intervention.

We note that there was no significant effect of condition for children's rating of rational helpers and rational punishers. However, in contrast to Study 1 which aimed at directly 
comparing helpers and punishers, Study 2 with its focus on rational versus irrational intervention asked children to evaluate helpers and punishers as a between subject variable. As a consequence, children did not see helping and punishment side by side, which might explain why there was no significant difference in their evaluations of helpers and punishers- as long as helping and punishment reduced inequality.

Results of Study 2 address outstanding questions from Study 1 by showing that children's preference cannot be explained by a mere preference for givers over takers. This preference should have resulted in a non-significant difference in children's liking between rational and irrational helpers. This alternative hypothesis is refuted by the current findings that children attended to whether helping decreased or increased inequality. This study also rules out that children preferred helpers to punishers because helping maximizes the total number of resources. This alternative account predicted that there should be no difference in preference between rational and irrational third parties. This is refuted by children preferring rational over irrational third parties in both the helping-only and the punishment-only conditions. Also, here, children attended to the impact of third-party's action on fairness when evaluating them.

However, one could argue that it is still unclear how children think about third-party interventions because Study 1 and 2 always asked children to evaluate third-party actors, not the act of intervention per se. Specifically, it is possible that children might evaluate actors and actions differently. One hypothesis is that children would evaluate punishing action as negative or neutral. This result would suggest that, although children rate punishers positively, they do not view punishment as a preferable way to intervene against unfairness perhaps due to the observed aggression (i.e., taking behavior) in punishment. 
Alternatively, children would like punishing action more than helping action. That is, what children think is a proper way to intervene can differ from who they want to associate with. For example, even if they like helpers better than punishers as their friend, it is still possible they endorse punishment more than helping to uphold cooperative group norms and prevent future transgressions.

The purpose of Study 3 was (1) to replicate children's preference for helpers over punishers and (2) to examine whether children evaluate actions differently from the agents performing these actions or their evaluations of the actions correspond to their evaluation of the people performing them.

\section{Study 3: How Do Children Evaluate Helping and Punishing Actions?}

\subsection{Method}

6.1.1. Participants. Our final sample were $N=805$ - to 9-year-old children $(M=89.17$ months, range $=59-118$ months, $n=16$ participants in each age group, 40 female). Children were recruited and tested at a museum in a Midwest town in the US. Demographic information such as race, education, and income were not asked. Ten additional children were excluded because they failed to identify the helper and punisher during both memory check questions (5), they did not endorse sharing (3) or there was interference from a parent or a friend (2).

6.1.2. Experimental design and procedure. Children heard the identical story with a third-party punisher and a helper as in Study 1. The difference from Study 1 was that we included two new measures to examine children's evaluations of each third-party's action: (1) children's agreement with punishing and helping actions on the Likert scale, ranging from -3 (totally disagree) to +3 (totally agree) and (2) their forced-choice preference between the two actions (punishing vs. helping). In Study 3, we excluded trait attribution measures and two of the 
three forced-choice questions used in Study 1 and 2 (i.e., friend, party) to focus our research question on evaluations of actions. However, we still kept our primary measures (i.e., Likert scale ratings about helpers and punishers and who they "like better" between the two actors) in Study 3 to replicate children's preference for helpers over punishers.

After seeing the divider's unfair allocation, children were asked to rate their agreement with helping and punishing actions on the 7-point smiley face Likert scale. For example, we asked "Some children say that [the third-party actor's name] should take two candies away from [the unfair divider's name]. What do you think about the idea?". Subsequently, the same child was asked "Some children say that [the third-party actor's name] should give two candies to [the recipient's name]. What do you think about the idea?".

Furthermore, children were forced to choose what the third-party actor should do between punishment of the unfair divider and helping of the recipient ("What do you think [the third-party actor's name] should do? Do you think he should take two candies away from [the unfair divider's name] or give two candies to [the recipient's name]?"). Importantly, children were asked to indicate their evaluations about punishing and helping actions before they heard about the actual intervention decision that the third-party actor made.

We counterbalanced the order of the questions (ask punishing first vs. ask helping first), the order of agreement scale (agreement first vs. disagreement first) and the order of practice trials (practice positive statement first vs. practice negative statement first).

\subsection{Results}

6.2.1. Evaluations in Likert scale ratings. In terms of third-party actors, children's evaluations of helpers $(M=2.10, S D=1.21)$ and punishers $(M=1.09, S D=1.77)$ differed significantly from neutral (one sample t-tests, $t(79)=15.55, p<.001$ and $t(79)=5.49, p<.001$, 
respectively), suggesting that both the helper and punisher were rated positively. These results replicated the findings from Study 1.
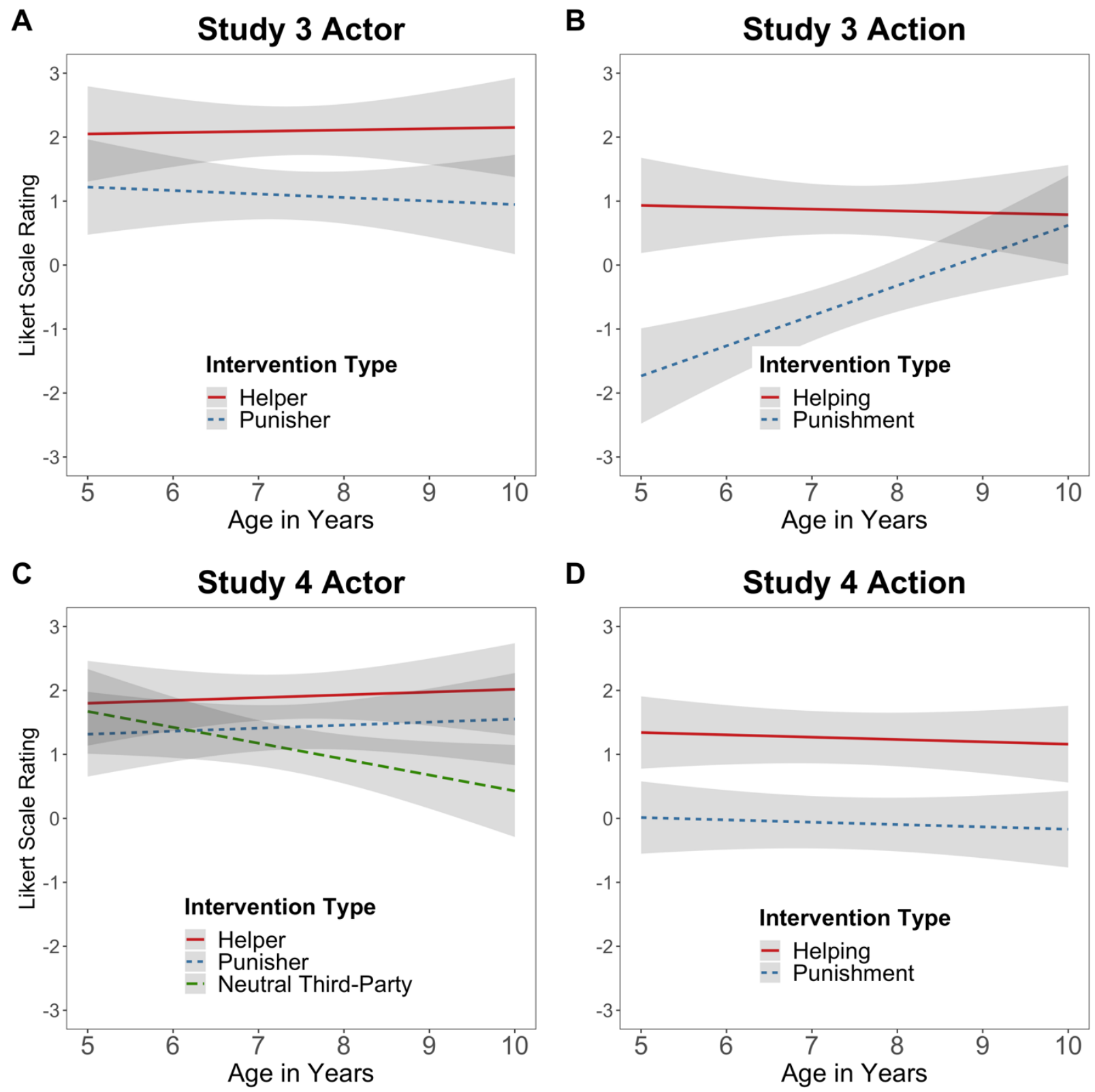

Figure 3. Likert scale ratings in Study 3 and 4.

(A) Likert scale ratings of helpers and punishers in Study 3. (B) Likert scale ratings of helping and punishing actions in Study 3. (C) Likert scale ratings of helpers, punishers and neutral third parties in Study 4. (B) Likert scale ratings of helping and punishing actions in Study 4. 
In terms of third-party actions, children's evaluations of helping $(M=0.86, S D=1.95)$ differed significantly from neutral, suggesting that they viewed helping action positively, $t(79)=$ 3.95, $p<.001$, whereas punishment $(M=-0.59, S D=2.06)$ differed significantly from neutral in the opposite direction, suggesting that children viewed punishing action negatively; $t(79)=$ $2.55, p<.05$.

The results from a full LMM on the Likert scale ratings with the target (actor vs. action), intervention type (helping vs. punishment), age and interactions among the predictors as fixed effects and subject ID as a random effect revealed that there is a significant three-way interaction effect involving target, intervention type and age $\left(\operatorname{LRT}, \chi^{2}(1)=5.32, p<.05\right)$. To better understand the three-way interaction effect, we ran a separate LMM depending on the target (actor vs. action).

When it comes to actors, there was a significant main effect of intervention type (LRT, $\chi^{2}$ $(1)=22.78, b=-1.01, S E=0.20, p<.001)$, suggesting that children liked helpers more than punishers (see Figure 3A). The findings show that children liked helpers more than punishers regardless of their age.

In terms of children's evaluations of actions, we found a significant interaction between intervention type and age (LRT, $\chi^{2}(1)=5.54, p<.05$; see Figure $\left.3 \mathrm{~B}\right)$. To unpack this two-way interaction, we ran separate linear models for helping action and punishing action. For evaluations of the act of helping, there was a non-significant effect of age, $F(1,78)<1, p>.84$, indicating that children rated helping positively regardless of their age. However, regarding the act of punishment, we found a significant effect of age, $F(1,78)=9.68, b=0.04, S E=0.01, p<$ .01. That is, with increasing age, children tend to view punishing action more positively. Further inspections of confidence intervals revealed that from 102 months of age ( 8.5 years), the 
confidence interval of punishing action ratings started to overlap with that of helping action ratings (helping $M=0.83,95 \% \mathrm{CI}[0.36,1.30]$; punishment $M=-0.08,95 \% \mathrm{CI}[-0.56,0.39]$ ). This finding tentatively suggests that a tendency to view punishment as a proper way to intervene against unfairness becomes reliable between ages 8 and 9 (but see our follow-up Study 4 results 7.2.1 for a discussion of the robustness of this effect).

6.2.2. Social preference in forced-choice questions. When asked who they liked better, a majority (71\%) of children chose helpers over punishers (binomial test, 95\% CI [0.60, 0.81], $p$ $<.001)$, replicating the results from Study 1 . When asked to choose between two third-party actions, a majority (63\%) of children chose the helping action over the punishing action (binomial test, 95\% CI [0.51, 0.73], $p<.05$ ), reporting that the third-party actor should help the recipient rather than to punish the unfair divider. The results from a GLM indicated that children preferred helping over punishment irrespective of the target (actor vs. action) or their age (see the supplementary material for detailed analyses).

\subsection{Discussion of Study 3}

In Study 3, we replicated a preference for helpers over punishers in children. Both Likertscale and forced-choice measures suggest that children like third-party helpers better than punishers irrespective of their age.

A new feature of Study 3 was that it assessed children's evaluations about third-party actions. We found that 5- to 9-year-olds evaluated helping action positively regardless of their age. By contrast, children's evaluation of punishing action became more positive between 8 and 9 years of age. However, we did not find a similar age-related trend in the forced-choice question, in which children had to choose which action is a better way to intervene. Here, most children chose helping over punishing action regardless of their age. 
Overall, our findings suggest that across all age groups, children prefer helping over punishment. Even if children older than 8 start to view punishment more positively than younger children do, they still prefer helping over the punishing action when they must choose only one type of intervention.

In Study 1 and 3, a major finding was that children view punishers positively, but they do not prefer punishers as much as they prefer helpers. However, it is still unclear whether children genuinely like third-party punishers. One possibility is that children rated punishers positively because of their general positivity bias towards any human characters. In other words, children's positive ratings of punishers might be inflated because of their mere liking of human characters in general, not because of the punishment the character performed.

Study 4 was designed to address this possibility by introducing a neutral third-party. If children's positive evaluations of punishers reflect their genuine liking, we would expect that children will like punishers more than the neutral third-party character. This result would suggest that punishers gain additional reputational benefits by enacting punishment. Alternatively, if their positive evaluations of punishers are a mere positivity bias towards human characters irrespective of their actions, children should like the neutral third-party as much as the punisher. Such an outcome would suggest that punishers do not gain any additional reputations by enacting punishment.

The purpose of Study 4 was to replicate Study 3 and to assess if punishers gain additional positive evaluations compared to neutral third parties.

7. Study 4: Do Children Evaluate Punishers More Positively Than Neutral Third Parties? 
7.1.1. Participants. Our final sample were $N=82$ - to 9 -year-old children $(M=88.30$ months, range $=60-118$ months, $n=17$ 5-year-olds, $n=17$ 6-year-olds, $n=17$ 7-year-olds, $n=$ 17 8-year-olds, $n=149$-year-olds, 42 female). Children were drawn from the same population and tested in the same context as children from Study 3. Five additional children were excluded because they failed to identify the third-party actors during both memory check questions.

7.1.2. Experimental design and procedure. The procedure was identical to that of Study 3 except that children were introduced to a neutral third-party. At the beginning of the story, the experimenter said that the neutral third-party character is busy and cannot join the candy game that the other four characters - a divider, a recipient, a helper, and a punisher — are involved with. Then, the neutral third party left and did not appear during the rest of the story. That is, the neutral third party neither watched any of the events nor got involved in any way. The neutral third-party character was presented to children again along with the other four characters when the experimenter asked the test questions. Therefore, it appeared only twice during the entire testing session: At the beginning and the end (test phase) of the study.

All the measures were identical to those used in Study 3 except that we added (1) the Likert scale rating of the neutral third-party and (2) two additional forced-choice preference questions involving the neutral third-party (helper vs. neutral, punisher vs. neutral).

\subsection{Results}

7.2.1. Evaluations in Likert scale ratings. Children's evaluations of helpers $(M=1.90$, $S D=1.60)$, punishers $(M=1.43, S D=1.70)$ and neutral third parties $(M=1.09, S D=1.62)$ differed significantly from the neutral value of zero (one sample t-tests, $t(81)=10.77, p<.001$; $t(81)=7.60, p<.001 ; t(81)=6.07, p<.001$, respectively), suggesting that all three third-party actors were viewed positively (see Figure 3C). 
The results from an LMM with age, intervention type and interactions with the predictors as fixed effects and subject ID as a random effect revealed that there was a significant effect of intervention type $\left(\mathrm{LRT}, \chi^{2}(2)=11.46, p<.01\right)$. The results indicated that children liked helpers more than punishers $(b=-0.48, S E=0.24, p<.05)$ and liked helpers more than neutral third parties $(b=-0.82, S E=0.24, p<.001)$. However, there was no difference in evaluations between punishers and neutral third parties $(b=-0.34, S E=0.24, p>.15)$.

When it comes to actions, children's evaluations of helping $(M=1.26, S D=1.97)$ differed significantly from zero, suggesting that they viewed helping action positively (one sample t-test, $t(81)=5.76, p<.001)$. This result replicated the findings from Study 3. By contrast, children's ratings of punishment $(M=-0.07, S D=2.20)$ did not differ from zero, suggesting that children viewed the punishing action neutrally (one sample t-test, $t(81)=-0.30, p$ $>.76)$.

Next, to test the effect of target (actor vs. action) on the ratings, we ran an LMM on the Likert scale ratings with the target (actor vs. action), intervention type (helping vs. punishment), age and interactions with the predictors as fixed effects and subject ID as a random effect. There was a significant interaction between the target and intervention type (LRT, $\chi^{2}(1)=4.99, p<$ .05 ; see Figure 3D).

To unpack the two-way interaction between the target (actor vs. action) and intervention type (helping vs. punishment), we ran separate LMMs for the actor and action, respectively. Children liked helpers more than punishers $\left(\chi^{2}(1)=4.61, b=-0.48, S E=0.22, p<.05\right)$. Also, they liked helping action more than punishing action $\left(\chi^{2}(1)=22.45, b=-1.33, S E=0.26, p<\right.$ .001). That is, regardless of target (actor vs. action), children liked helping more than punishment. The interaction effect between the target and intervention type was because 
children's preference for helping over punishment is more pronounced in their ratings of actions than those of actors.

7.2.2. Social preference in forced-choice questions. When asked who they liked better, children's preference for helpers over neutral third parties increased with age (from $41 \%$ in 5 year-olds to $100 \%$ in 9 -year-olds). Similarly, the preference for punishers over neutral third parties increased from $29 \%$ to $86 \%$, and the preference for helpers over punishers increased from $35 \%$ to $93 \%$ (see Figure S4 in the supplementary material for values broken down by age group).

A

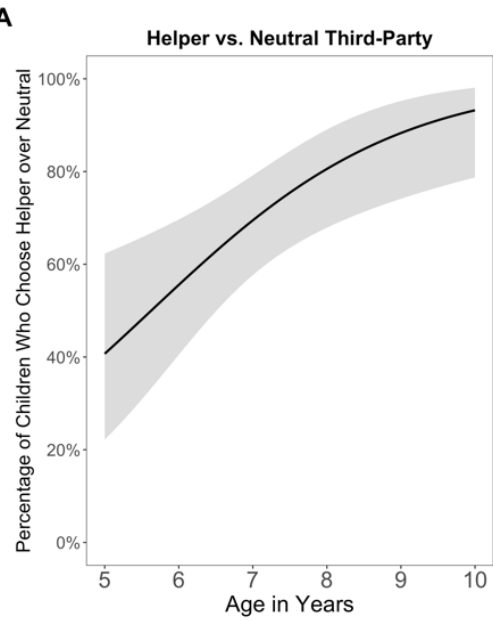

B

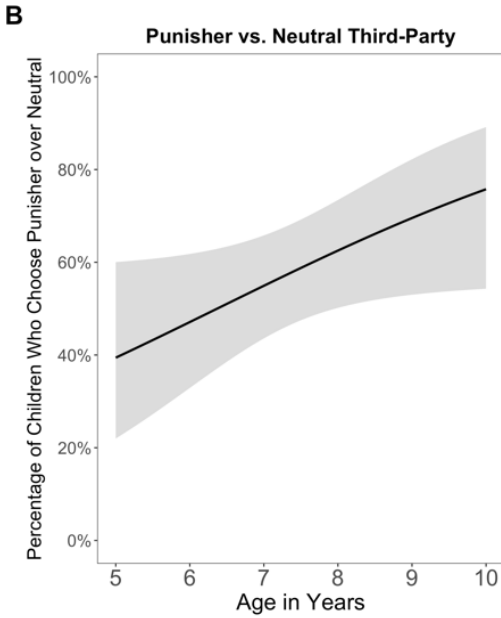

C

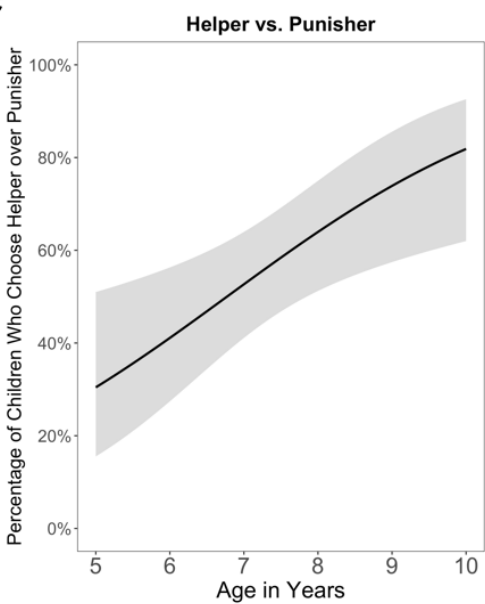

Figure 4. Forced-choice social preferences in Study 4.

(A) Higher percentage indicates children's preference for helpers over neutral third parties. (B) Higher percentage indicates children's preference for punishers over neutral third parties. (C) Higher percentage indicates children's preference for helpers over punishers.

To examine the effect of age on children's forced-choice preferences, we ran three separate GLMs on children's choice in (1) helper vs. neutral third-party, (2) punisher vs. neutral third-party, and (3) helper vs. punisher. First, the results from a GLM with a binary response term $($ helper $=1$, neutral third-party $=0)$ indicated that age predicted children's preference (LRT, $\left.\chi^{2}(1)=11.04, b=0.05, S E=0.02, p<.001\right)$. That is, children are more likely to prefer helpers 
over neutral third parties as they grow older (see Figure 4A). Closer inspections of confidence intervals revealed that confidence intervals no longer overlap with chance from 79 months $(6.6$ years) $(M=0.64,95 \% \mathrm{CI}[0.51,0.75])$.

Second, the results from a GLM with a binary response term (punisher $=1$, neutral thirdparty $=0)$ revealed that age predicted children's preference $\left(\right.$ LRT, $\chi^{2}(1)=4.06, b=0.03, S E=$ $0.01, p<.05$ ); Figure 4B), suggesting that children were more likely to prefer punishers over neutral third parties with age. Confidence intervals no longer overlap with chance from 96 months (8 years) of age $(M=0.63,95 \% \mathrm{CI}[0.502,0.73])$.

Third, the results from the GLM with a binary response term $($ helper $=1$, punisher $=0$ ) revealed that age significantly predicted children's preference $\left(\mathrm{LRT}, \chi^{2}(1)=8.57, b=0.04, S E=\right.$ $0.01, p<.01$; Figure 4C), suggesting that their preference for helpers to punishers increased with their age. From 95 months of age (7.9 years), confidence intervals no longer included chance ( $M$ $=0.63,95 \% \mathrm{CI}[0.51,0.74])$.

When asked to choose between two actions, most children (70\%) chose helping over the punishing action (binomial test, 95\% CI [0.58, 0.79], $p<.001$ ), replicating the findings from Study 3. The results from a GLMM indicated that there was no effect of age on children's choice between helping and punishing action, suggesting that children prefer helping over punishment regardless of age (see the supplementary material for analyses).

\subsection{Discussion of Study 4}

Study 4 replicated the findings from Study 3 that children liked helpers more than punishers on the Likert scale ratings and that they preferred helping action over punishing action. However, unlike in Study 3 in which children rated punishment more positively with age, we did not find the same age effect in Study 4. That is, regardless of their age, children rated punishment 
neutrally on the Likert scale. We conclude that the age effect found in Study 3 was not reliable enough because of the small sample size in each age group or the narrow age range.

We found that children liked helpers more than neutral third parties. Interestingly, children's ratings of punishers and neutral third parties did not differ significantly from each other, suggesting that punishers do not receive any additional positive evaluations from children compared to neutral third parties. In the forced-choice task, however, children's tendency to prefer punishers over neutral third parties becomes stronger around age 8 . These results suggest that the enactment of punishment does not entail additional reputational benefits in children younger than 8 .

In contrast to Study 1 and 3, we did not replicate children's preference for helpers over punishers in the forced-choice question. In Study 4, children's preference for both third parties did not differ significantly, and their preference for helpers to punishers becomes stronger around age 8 . We speculate that young children might have had difficulties with comparing three pairs of characters (Note that we found an age effect in all three forced-choice tasks; see Figure 4). The confusion might have been more pronounced in young children when they had to compare three different characters with each other in the forced-choice tasks than when they had to report their liking for one character at a time on the Likert scale in which we did not find an age effect.

\section{General Discussion}

This series of studies provides new evidence on children's evaluations of third-party interventions against fairness norm violations. This was possible, in part, because of our novel comparison between children's evaluations of those who punish selfish resource dividers with those who help recipients of selfish resource allocations. We started with the recent evidence showing that adults generally view helpers more favorably compared to punishers (Jordan et al., 
2016; Patil et al., 2018; Raihani \& Bshary, 2015a). For a first look at this phenomenon in children, we tested two competing hypotheses: One hypothesis assumed developmental continuity, proposing that this preference might be a deep-seated psychological phenomenon that is present already in children. The counterhypothesis conjectured that there would be a developmental discontinuity, with young children focusing more on superficial features of the actions, judging helpers as positive and the more aggressive punishers as negative, while older children acknowledge potential benefits of punishment and therefore evaluating punishers positively, and perhaps as positively as helpers.

Overall, the current findings are consistent with the first hypothesis that children would share a similar preference with adults. Across studies, we found that children between 5 and 9 years of age evaluated punishers positively. However, they liked helpers more than punishers. For example, children rated helpers more positively than punishers on the Likert scale (Study 3 and 4). Similarly, they chose helpers over punishers in the forced-choice measures (Study 1 and 3). Furthermore, in Study 1, we found that children inferred warmth-related traits (generosity, empathy) from helpers, while they inferred conflict-related traits (aggression, norm enforcement) from punishers, showing their reasoning behind the preference for helpers.

We also ruled out two alternative hypotheses according to which children's preference for helpers could be due to their preference for givers or for resource maximizers, respectively. Contrary to these alternative hypotheses, in Study 2, we found that children aged 7 years and older liked rational third parties who decreased inequality more than irrational ones who increased inequality. This suggests that their preference for helpers can neither be explained by a mere preference for givers over takers nor by a preference for resource maximizers. In fact, from 
7 years on, children conceived of third-party interventions as aimed at identifying a proper target to reduce inequality rather than as indiscriminate giving or resource maximizing.

Furthermore, we found that children's preference for helping over punishment is not just limited to judgments of third-party actors. When we assessed children's preference for the action per se, they liked helping actions more than punishing actions. Helping actions were always rated positively while punishing actions were rated negatively or neutrally (Study 3 and 4). We found similar results in the forced-choice task: Children chose helping over punishment irrespective of their age (Study 3 and 4).

The current study contributes to the literature by moving beyond the focus on punishment alone and probing children's thinking about punishment and helping side by side. Prior developmental research focused on comparing punishers with third parties such as onlookers who choose not to intervene after witnessing a transgression (e.g., Vaish et al., 2016) or givers who reward a transgressor (e.g., Hamlin et al., 2011), which might have led to inflating children's preference for punishers. Instead, the current study compared punishment with helping, a valid and common form of third-party intervention. Additionally, our study assessed children's evaluations of punishment intervention per se and revealed a subtle but meaningful difference in understanding punishers vs. punishment, which was especially remarkable in young children. With the use of various measures and comparisons, the current study provided a more comprehensive understanding of the development of third-party punishment in children.

\subsection{Limitations and future directions}

One potential concern is that the developmental pattern found in the current experiments is due to cognitive demands inherent in our tasks, rather than reflecting changes in fairness judgments per se. For example, younger children might have had difficulty keeping track of the 
identities and behaviors of each actor in our story. However, this is unlikely for two reasons. First, we included two memory checks, revealing that most children understood the events and identified actors in the story correctly (90\% in Study 1 and 2, 94\% in Study 3 and 4), while the few who failed both memory checks were excluded from our analyses. Second, our data do not support the idea that young children found the task too difficult. If young children had problems with understanding the story, they should have shown results different from those of older children across a wide range of measures. However, in the majority of our measures, we did not find significant age differences. For example, regardless of their age, children evaluated both helpers and punishers positively and preferred helpers over punishers. Additionally, there were no age differences in children's ability to attribute relevant traits to a third-party (except for attribution of norm enforcement in Study 1; see the supplementary material for analyses). Hence, it is unlikely that the task difficulty affected a few specific measures selectively. In summary, we believe that the age differences found in our measures reflect the development of children's understanding of fairness and third-party interventions rather than the cognitive demands of our tasks.

The current study elucidates the development of children's evaluations of third-party punishment and helping in the context of fairness norm violations. One critical question to consider is why children and adults show this preference. A possible explanation is that people prefer those who show an empathetic concern for the well-being of others. People might consider helpers as someone who is trustworthy and dependable when in need, and thus want to associate with helpers rather than with punishers (Jordan et al., 2016; Patil, Dhaliwal, \& Cushman, 2018). Another reason could be that helping is regarded as an empathetic and generous act, whereas punishment, even though justified, is regarded as aggressive. As a consequence, people may 
acknowledge that punishers are a necessary asset to uphold group norms but may be less likely to choose them as social partners due to the perceived aggression or dominance they display when enforcing norms (Gordon, Madden, \& Lea, 2014). Another possibility is that children prefer those who establish equality and maximize resources simultaneously. One potential reason for children preferring helpers over punishers is that helpers not only establish equality but also maximize resources (enlarge the pie), whereas punishers establish equality but minimize available resources. Not surprisingly, adults seem to have a similar preference: they prefer an option that not only establishes equality but enlarge the pie at the same time over a punitive intervention (FeldmanHall et al., 2014; Heffner \& FeldmanHall, 2019). Our study suggests that children do not merely like anyone who enlarges the pie (e.g., when helping increases inequality). However, it is still possible and indeed likely that children endorse resource maximization per se, as long as it does not increase inequality. Future research should investigate reasons underlying the preference for helping over punishment in children.

Another critical question is whether children's preference for helpers found in fairness norm violations in the current study can be generalized to other moral contexts. For example, in the context of physical harm, children might prefer punishment over helping because the physical harm inflicted on the victim might be considered as irrecoverable and thus not compensable. On the other hand, physical harm also often triggers an urge to comfort a victim or relieve pain, so children might regard punishment of perpetrators without a remedy for the victim as cruel. Similar arguments can be made about property damage or theft, opening many possibilities for future research across diverse moral domains.

Last but not least, future research should investigate how children from different populations and cultures reason about and engage in third-party punishment. While we selected 
children from the US based upon prior studies, there are cross-cultural variations in fairness norms and behaviors across both adults and children (Blake et al., 2015; Henrich et al., 2006; Herrmann, Thöni, \& Gächter, 2008; House et al., 2013). Therefore, it is a critical task for future research to assess similarities and differences in the developmental trajectory of children's third-party punishment across different populations. 


\section{References}

Balliet, D., Mulder, L. B., \& Van Lange, P. A. M. (2011). Reward, punishment, and cooperation: A meta-analysis. Psychological Bulletin, 137(4), 594-615. doi:10.1037/a0023489

Bates, D., Maechler, M., Bolker, B., \& Walker, S. (2015). Fitting linear mixed-effects models using lme4. Journal of Statistical Software, 67, 1-48. doi:10.18637/jss.v067.i01.

Baumard, N., André, J. B., \& Sperber, D. (2013). A mutualistic approach to morality: The evolution of fairness by partner choice. Behavioral and Brain Sciences, 36, 59-78. doi:10.1017/S0140525X11002202

Blake, P. R., \& McAuliffe, K. (2011). “I had so much it didn't seem fair” Eight-year-olds reject two forms of inequity. Cognition, 120, 215-224. doi:10.1016/j.cognition.2011.04.006

Blake, P. R., McAuliffe, K., Corbit, J., Callaghan, T. C., Barry, O., Bowie, A., Kleutsch, L., Kramer, K. L., Ross, E., Vongsachang, H., Wrangham, R., \& Warneken, F. (2015). The ontogeny of fairness in seven societies. Nature, 528, 258-261. doi:10.1038/nature15703

Boyd, R., Gintis, H., Bowles, S., \& Richerson, P. J. (2003). The evolution of altruistic punishment. Proceedings of the National Academy of Sciences of the United States of America, 100, 3531-3535. https://doi.org/10.1073/pnas.0630443100

Bregant, J., Shaw, A., \& Kinzler, K. D. (2016). Intuitive jurisprudence: Early reasoning about the functions of punishment. Journal of Empirical Legal Studies, 13, 693-717. https://doi.org/10.1111/jels. 12130

Chavez, A. K., \& Bicchieri, C. (2013). Third-party sanctioning and compensation behavior: Findings from the ultimatum game. Journal of Economic Psychology, 39, 268-277. https://doi.org/10.1016/j.joep.2013.09.004 
Fehr, E., \& Gächter, S. (2002). Altruistic punishment in humans. Nature, 415, 137-140. doi:10.1038/415137a

Fehr, E., Fischbacher, U., \& Gächter, S. (2002). Strong reciprocity, human cooperation, and the enforcement of social norms. Human Nature, 13, 1-25. https://doi.org/10.1007/s12110-002$1012-7$

Fehr, E., \& Fischbacher, U. (2003). The nature of human altruism. Nature, 425, 785-791. https://doi.org/10.1038/nature02043

Fehr, E., \& Fischbacher, U. (2004a). Third party punishment and social norms. Evolution and Human Behavior, 25, 63-87. doi:10.1016/S1090-5138(04)00005-4

Fehr, E., \& Fischbacher, U. (2004b). Social norms and human cooperation. Trends in Cognitive Sciences, 8, 185-190. https://doi.org/10.1016/j.tics.2004.02.007

FeldmanHall, O., Sokol-Hessner, P., Van Bavel, J. J., \& Phelps, E. A. (2014). Fairness violations elicit greater punishment on behalf of another than for oneself. Nature Communications, 5 , 5306. https://doi.org/10.1038/ncomms6306

Gordon, D. S., Madden, J. R., \& Lea, S. E. G. (2014). Both loved and feared: Third party punishers are viewed as formidable and likeable, but these reputational benefits may only be open to dominant individuals. PLoS ONE, 9, 1-10. doi:10.1371/journal.pone.0110045

Guala, F. (2012). Reciprocity: Weak or strong? What punishment experiments do (and do not) demonstrate. Behavioral and Brain Sciences, 35, 1-15. https://doi.org/10.1017/S0140525X11000069

Gummerum, M., \& Chu, M. T. (2014). Outcomes and intentions in children's, adolescents', and adults' second- and third-party punishment behavior. Cognition, 133, 97-103. doi:10.1016/j.cognition.2014.06.001 
Gurerk, O., Irlenbusch, B., \& Rockenbach, B. (2006). The competitive advantage of sanctioning institutions. Science, 312, 108-111. doi:10.1126/science.1123633

Deschamps, T. D., Eason, A. E., \& Sommerville, J. A. (2015). Infants associate praise and admonishment with fair and unfair individuals. Infancy, 1-27. https://doi.org/10.1111/infa.12117

Hamlin, J. K., Wynn, K., Bloom, P., \& Mahajan, N. (2011). How infants and toddlers react to antisocial others. Proceedings of the National Academy of Sciences of the United States of America, 108, 19931-6. doi:10.1073/pnas.1110306108

Heffner, J., \& FeldmanHall, O. (2019). Why we don't always punish: Preferences for nonpunitive responses to moral violations. Scientific Reports, 9, 1-13.

https://doi.org/10.1038/s41598-019-49680-2

Henrich, J., McElreath, R., Barr, A., Ensminger, J., Barrett, C., Bolyanatz, A., Bolyanatz, A., Cardenas, J.C., Gurven, M., Gwako, E., Henrich., N., Lesorogol, C., Marlowe, F., Tracer, D., \& Ziker, J. (2006). Costly punishment across human societies. Science, 312, 1767-1770. doi:10.1126/science. 1127333

Hermann, B., Thöni, C., \& Gächter, S. (2008). Antisocial punishment across societies. Science, $319,1362-1367$.

House, B. R., Silk, J. B., Henrich, J., Barrett, H. C., Scelza, B. A., Boyette, A. H., Hewlett, B.S., McElreath, R., \& Laurence, S. (2013). Ontogeny of prosocial behavior across diverse societies. Proceedings of the National Academy of Sciences, 110, 14586-14591. doi:10.1073/pnas. 1221217110 
Jordan, J. J., McAuliffe, K., \& Warneken, F. (2014). Development of in-group favoritism in children's third-party punishment of selfishness. Proceedings of the National Academy of Sciences, 111, 12710-12715. doi:10.1073/pnas.1402280111

Jordan, J., Hoffman, M., Bloom, P., \& Rand, D. (2016). Third-party punishment as a costly signal of trustworthiness. Nature, 530, 473-476. doi:10.1038/nature16981

Kanakogi, Y., Inoue, Y., Matsuda, G., Butler, D., Hiraki, K., \& Myowa-Yamakoshi, M. (2017). Preverbal infants affirm third-party interventions that protect victims from aggressors. Nature Human Behaviour, 1, 0037. https://doi.org/10.1038/s41562-016-0037

Krasnow, M. M., Delton, A. W., Cosmides, L., \& Tooby, J. (2016). Looking under the hood of third-party punishment reveals design for personal benefit. Psychological Science, 1-14. https://doi.org/10.1177/0956797615624469

Liu, D., \& Vanderbilt, K. E. (2013). Children learn from and about variability between people. In M. R. Banaji, \& S. A. Gelman (Eds.), Navigating the social world: What infants, children, and other species can teach us (pp. 197-200). New York, NY: Oxford University Press.

McAuliffe, K., Jordan, J. J., \& Warneken, F. (2015). Costly third-party punishment in young children. Cognition, 134, 1-10. doi:10.1016/j.cognition.2014.08.013

Meristo, M., \& Surian, L. (2014). Infants distinguish antisocial actions directed towards fair and unfair agents. PLoS ONE, 9, 1-7. https://doi.org/10.1371/journal.pone.0110553

Molleman, L., Kölle, F., Starmer, C., \& Gächter, S. (2019). People prefer coordinated punishment in cooperative interactions. Nature Human Behaviour, 3, 1145-1153. https://doi.org/10.1038/s41562-019-0707-2 
Nelissen, R. M. A. (2008). The price you pay: cost-dependent reputation effects of altruistic punishment. Evolution and Human Behavior, 29, 242-248. https://doi.org/10.1016/j.evolhumbehav.2008.01.001

Nelissen, R. M. A., \& Zeelenberg, M. (2009). Moral emotions as determinants of third-party punishment: Anger, guilt, and the functions of altruistic sanctions. Judgment and Decision Making, 4, 543-553.

Patil, I., Dhaliwal, N., \& Cushman, F. A. (2018, May 23). Reputational and cooperative benefits of third-party helping. doi:10.31234/osf.io/c3bsj

Petersen, M. B., Sell, A., Tooby, J., \& Cosmides, L. (2010). Evolutionary psychology and criminal justice: A recalibrational theory of punishment and reconciliation. In Høgh-Olesen, H. (Ed.), Human Morality and Sociality Evolutionary and Comparative Perspectives (pp. 72-131). New York: Palgrave MacMillan.

Pinheiro J, Bates D, DebRoy S, Sarkar D, R Core Team (2018). nlme: Linear and Nonlinear Mixed Effects Models. R package version 3.1-137, <URL: https://CRAN.Rproject.org $/$ package $=$ nlme $>$.

Raihani, N. J., \& Bshary, R. (2015a). Third-party punishers are rewarded, but third-party helpers even more so. Evolution, 69, 993-1003. doi:10.1111/evo.12637

Raihani, N. J., \& Bshary, R. (2015b). The reputation of punishers. Trends in Ecology and Evolution, 30, 98-103. https://doi.org/10.1016/j.tree.2014.12.003

R Core Team (2018). R: A language and environment for statistical computing. R Foundation for Statistical Computing, Vienna, Austria. URL https://www.R-project.org/. 
Smith, C. E., \& Warneken, F. (2016). Children's reasoning about distributive and retributive justice across development. Developmental Psychology, 52, 613- 628. doi:10.1037/a0040069

Stallen, M., Rossi, F., Heijne, A., Smidts, A., De Dreu, C. K. W., \& Sanfey, A. G. (2018). Neurobiological mechanisms of responding to injustice. Journal of Neuroscience, 38, 2944 2954. https://doi.org/10.1523/JNEUROSCI.1242-17.2018

Vaish, A., Missana, M., \& Tomasello, M. (2011). Three-year-old children intervene in thirdparty moral transgressions. The British Journal of Developmental Psychology, 29, 124-130. doi:10.1348/026151010X532888

Vaish, A., Herrmann, E., Markmann, C., \& Tomasello, M. (2016). Preschoolers value those who sanction non-cooperators. Cognition, 153, 43-51. doi:10.1016/j.cognition.2016.04.011

Yamagishi, T., Horita, Y., Mifune, N., Hashimoto, H., Li, Y., Shinada, M., ... Simunovic, D. (2012). Rejection of unfair offers in the ultimatum game is no evidence of strong reciprocity. Proceedings of the National Academy of Sciences of the United States of America, 109, 20364-20368. https://doi.org/10.1073/pnas.1212126109

Yamagishi, T., Li, Y., Fermin, A. S. R., Kanai, R., Takagishi, H., Matsumoto, Y., ... Sakagami, M. (2017). Behavioural differences and neural substrates of altruistic and spiteful punishment. Scientific Reports, 7, 1-8. https://doi.org/10.1038/s41598-017-15188-w

Yudkin, D. A., Van Bavel, J. J., \& Rhodes, M. (2020). Young children police group members at personal cost. Journal of Experimental Psychology: General, 149(1), 182-

191. https://doi.org/10.1037/xge0000613 